\title{
Fruit, vegetable consumption and blood pressure in healthy adolescents: A longitudinal analysis from the LabMed study
}

\author{
R. Rosário a,b,*, R. Santos c,d , L. Lopes ${ }^{\text {c }}$, C. Agostinis-Sobrinho ${ }^{\text {ce, }, \text {, }, ~ C . ~ M o r e i r a ~}{ }^{\text {c }}$, J. Mota c, \\ S. Póvoas ${ }^{g}$, A. Oliveira ${ }^{c}$, P. Padrão ${ }^{\text {h,i, }}$, P. Moreira ${ }^{\mathrm{c}, \mathrm{h}, \mathrm{i}}, \mathrm{S}$. Abreu ${ }^{\mathrm{c}, \mathrm{j}}$ \\ ${ }^{a}$ School of Nursing, University of Minho, Portugal \\ ${ }^{b}$ Health Sciences Research Unit-Nursing, Escola Superior de Enfermagem de Coimbra, Portugal \\ ${ }^{c}$ Research Centre in Physical Activity, Health and Leisure, Faculty of Sport, University of Porto, Portugal \\ ${ }^{d}$ Early Start, Faculty of Social Sciences, School of Education, University of Wollongong, Australia \\ ${ }^{e}$ Faculty of health Sciences, Klaipeda University, Lithuania \\ ${ }^{f}$ Physical Education, Physiotherapy and Dance, Federal University of the South of Brazil, Porto Alegre, Rio Grande do Sul, Brazil \\ ${ }^{g}$ Research Center in Sports Sciences, Health Sciences and Human Development, CIDESD, University Institute of Maia, ISMAI, Maia, Portugal \\ ${ }^{h}$ Faculty of Nutrition and Food Sciences, University of Porto, Portugal \\ ${ }^{i}$ Institute of Public Health, University of Porto, Portugal \\ ${ }^{j}$ Universidade Lusófona do Porto, Portugal
}

Received 1 February 2018; received in revised form 23 May 2018; accepted 24 May 2018

Handling Editor: A. Siani

Available online 31 May 2018

\section{KEYWORDS \\ Adolescents; \\ Blood pressure; \\ Fruit; \\ Vegetable}

\footnotetext{
* Corresponding author. Universidade do Minho, Escola Superior de Enfermagem, $3^{\circ}$ Piso - Edif. da Biblioteca Geral (BGUM), Campus de Gualtar, 4710-057, Braga, Portugal. Fax: +351 253601319.

E-mail address: rrosario@uminho.pt (R. Rosário).
}

\begin{abstract}
Background and aims: The associations between fruit and vegetable consumption and high blood pressure among adults are well studied. Nonetheless, data on the influence of a low consumption of fruit and vegetables on cardiovascular disease risk, particularly blood pressure, among healthy adolescents are scarce. Therefore, we aim to analyse the associations between fruit and/or vegetable intake and blood pressure over a two-year period in healthy adolescents. Methods and results: As part of a cohort, 606 adolescents from the LabMed Physical Activity study were evaluated in 2011 (baseline) and 2013 (follow-up). Blood pressure was measured according to standardized procedures and fruit and vegetable consumption was assessed with a food frequency questionnaire. Anthropometric variables, socioeconomic status, pubertal stage and lifestyle determinants were gathered and used as confounders. Prospective associations between fruit and/or vegetable intake and blood pressure were examined using generalized linear models. Girls who consumed more fruit at baseline had a significant decrease in diastolic blood pressure at follow-up [unstandardized beta: $-0.005 \mathrm{mmHg}(95 \% \mathrm{CI}:-0.01 ;-0.0002)(\mathrm{p}=0.038)$ ].

Conclusion: In apparently healthy adolescents, fruit intake may already start to have an effect in blood pressure. Girls who consumed more fruit exhibited lower levels of diastolic blood pressure. (c) 2018 The Italian Society of Diabetology, the Italian Society for the Study of Atherosclerosis, the Italian Society of Human Nutrition, and the Department of Clinical Medicine and Surgery, Federico II University. Published by Elsevier B.V. All rights reserved.
\end{abstract}


during puberty $[3,4]$ and most of the lifestyle habits are established during this period [5]. Therefore, it is important to find the modifiable determinants of elevated BP in order to implement lifestyle programs in youth to prevent the development of hypertension.

The relationship between nutritional intake and BP has been studied [6], but this approach does not account for the complexity of food consumption. Research found that higher consumption of certain foods, such as fruit and vegetables, is associated with lower systolic BP (SBP) $[7,8]$, in pre-puberty [9] and mainly in females [10]. Nonetheless, the exact mechanisms behind this association are not clear. Fruit and vegetables are high in potassium and magnesium, which have been associated with BP reductions [6]. In addition, fruit and vegetable consumption may reflect an overall healthier dietary pattern. Therefore, changes in BP may not be attributed to the effect of a single mineral $[7,11]$.

A previous prospective study on 95 children, aged 3-6 years, showed that higher consumption of fruit and vegetables during early childhood, especially when combined with dairy products, was associated with lower increases of BP during adolescence [7]. Similar results were found in a larger sample of pre-pubertal adolescents [9] and in older female children [12]. In a recent study, vegetable and fruit intake was negatively associated to SBP and DBP, respectively [8]. Likewise, longitudinal studies in adolescence have found that fruit and vegetable intake [10] and vegetable (but not fruit) [13] were associated with decreases in BP in young adulthood. Nonetheless, none of these studies investigated the independent effects of fruit and/or vegetables on BP in a large sample of healthy adolescents, nor considered other important confounders such as cardiorespiratory fitness.

We hypothesized that in adolescents, higher intake of fruit and/or vegetables at baseline is negatively associated with BP at follow-up. Therefore, we aimed to analyse the association between fruit and/or vegetable intake and BP over a two-year period in healthy adolescents.

\section{Methods}

\section{Study design and participants}

Data for the present study was derived from the "Longitudinal Analysis of Biomarkers and Environmental Determinants of Physical Activity (LabMed Physical Activity Study)". This is a school-based prospective study carried out in the North Region of Portugal aiming at evaluating the combined effects of fitness and dietary intake on BP. The full description of the study is reported elsewhere [14]. Briefly, 1229 adolescents aged $12-18$ years participated in the study and 1017 completed baseline assessments in 2011; of those, 893 (87.8\% participation) and 734 subjects (72.2\% participation) were re-evaluated one and two years later, respectively. The present study considered a sub-sample of adolescents $(\mathrm{n}=734)$ with information on BP measured at baseline and at two-year follow-up (in 2013). After exclusion of the participants with missing information of dietary intake ( $\mathrm{n}=128), 606$ adolescents (314 males) aged 12 to 18 years-old were included in the final analysis (please see supplementary figure).

\section{Ethical and legal requirements}

The study was conducted in accordance with the World Medical Association's Helsinki Declaration for Human Studies. The Portuguese Data Protection Authority (1112434/2011), the Portuguese Ministry of Science and Education (0246200001/2011) and the Faculty of Sport, University of Porto, approved the study. All participants in this study were informed of the study goals, and written informed consent was obtained from adolescents and their parents or guardians.

\section{Assessments}

\section{Dietary intake}

Dietary intake was measured with a self-administered semi-quantitative food frequency questionnaire (FFQ), which was designed in accordance with criteria laid out by Willett [15] and adapted to include a variety of typical Portuguese food items. This version of the questionnaire covered the previous twelve months and comprised ninety-one food items or beverage categories. For each item, the questionnaire offered nine frequency response options, ranging from 'never' to 'six or more times per day', and standard portion size and seasonality. In a freeresponse section, participants could list any foods not listed in the questionnaire. Energy and nutritional intake were estimated regarding to respondents' ratings of the frequency, portion and seasonality of each item, using the software Food Processor Plus (ESHA Research Inc., Salem, OR, US) and including typical Portuguese foods and beverages.

Total fruit and vegetable intake was calculated as the sum of fruit and vegetables consumed. Regarding fruit consumption, only whole fruit was included and fruit juice was excluded, because there may be an adverse association between fruit juice consumption and BP [16]. Vegetable intake included vegetables, legumes and vegetable soup, aggregated according to their nutritional similarities.

\section{Anthropometrics}

Anthropometric evaluation, was performed using standardized procedures [17]. For weight and height measurements, we used a digital scale (Tanita Inner Scan BC 532, Tokyo, Japan) and a portable stadiometer (Seca 213, Hamburg, Germany), respectively. Height was measured according to the Frankfort plane to the nearest $0.1 \mathrm{~cm}$, and body weight was measured to the nearest $0.1 \mathrm{~kg}$, with the participants lightly dressed and without shoes. Body mass index (BMI) was then computed as weight $(\mathrm{kg}) /$ height $(\mathrm{m})^{2}$. Waist circumference measurement was taken with the adolescent in a standing position, to the nearest $0.1 \mathrm{~cm}$, with a tape measure midway between the lower 
rib margin and the anterior superior iliac spine at the end of normal expiration [17]. Standard deviation scores (SDS) by age and sex were computed to all anthropometric variables.

\section{Blood pressure}

BP was measured after 5 min of rest, according to standard procedures [18,19], using a Dynamap vital signs monitor (model BP 8800, Critikon, Inc., Tampa, Florida). Appropriate cuff size was used for child's extremity [19]. Trained nurses performed the assessment on the nondominant arm and with the subjects seated in a relaxed position and with their feet resting flat on the ground. Two measurements were taken and the arithmetic mean of both readings was considered. In cases where the two measurements differed for a minimum of $10 \mathrm{mmHg}$, a third measure was taken and the first measurement rejected [18].

\section{other measurements}

Adolescents' socio-economic status was assessed with the family affluence scale. This scale was developed specifically to measure children and adolescents' socioeconomic status in the context of the Health Behaviour in School-Aged Children Study [20].

Pubertal stage based on secondary sex characteristics (ranging from stage I to $\mathrm{V}$ ) was self-assessed by adolescents, according to the criteria of Tanner and Whitehouse [21]. Girls assessed their breast and pubic hair development and boys their genital and pubic hair development.

The 20-m Shuttle Run Test (20 m SRT) was used to access cardiorespiratory fitness and $\mathrm{VO}_{2}$ max was calculated [22].

The accelerometers GT1M Actigraph (ActiGraph, Pensacola, Florida, USA) were used to obtain objective daily physical activity (PA) and sedentary behaviour over five consecutive days (three weekdays and two weekend days). The biaxial monitor was used according to international standards during waking hours and removed in water activities [23]. The epoch length was set to $2 \mathrm{~s}$ to allow a more detailed estimate of PA intensity. The program MAHUffe (please see www.mrc-epid.cam.ac.uk) allowed the analyses of the data and periods with $60 \mathrm{~min}$ of consecutive zeros were signalled as times in which the monitor was not worn. Raw activities, "counts", were processed for determination of time spent in the different PA intensities (expressed in mean counts.min-1). The cut-points proposed by Freedson and published by Trost et al. [24] were used to determine PA intensities.

\section{Statistical analysis}

Mean and standard deviations (SD) as well as median ( $25^{\text {th }}-75$ th percentiles) were used to describe the variables studied. One-way repeated measures Analysis Of Variance (ANOVA) was performed to assess differences between and within-subjects over time.
Bias in reported energy intake (misreporting) was evaluated according to the Goldberg cut-off method adapted by Black [25]. Basal metabolic rate was computed for each subject and the ratio energy intake and basal metabolic rate was used to define 95\% confidence limits. Cut-offs were achieved taking into account mean of PA level, number of days of dietary assessment, within-subject coefficient of variation in energy intake, between-subject variation in PA, and variation in basal metabolism rate. The mean PA level was calculated, from accelerometers data using counts.minutes $^{-1}$ and daily use time, reaching a mean value of $1.23 \mathrm{kcal}_{\text {day }}{ }^{-1}$. A number of 21 days of diet assessment was considered [25]. The within-subject coefficient of variation in energy intake was calculated considering mean and SD of energy intake and between-subject variation in PA considered mean and SD of PA level. A figure of $8.5 \%$ was used for the coefficient of variation of repeated basal metabolic rate measurements as suggested by Black [25]. We achieved 0.59 and 2.61 cut-off. Adolescents with energy intake/basal metabolic rate in this interval were classified as plausible reporters. Subjects with energy intake/basal metabolic rate below 0.59 and higher than 2.61, were categorized as under-reporters and over-reporters, respectively.

Associations between fruit or vegetables or fruit \& vegetable consumption at baseline and BP at follow-up were performed using generalized linear models (GLM). Hence, BP (diastolic-DBP or systolic-SBP) at follow-up was used as dependent variable, and adjustments included sex, age, height SDS, waist circumference SDS, socio-economic status, pubertal stage, cardiorespiratory fitness, misreporting, total energy intake, potassium, sodium and baseline measures of the dependent variable, to maximize precision. Since there were significant interactions for sex and fruit/ vegetable intakes analyses were performed by sex.

The data analysis was performed using SPSS, version 23.0 (SPSS Inc. Chicago, IL), with a 0.05 level of significance considered.

\section{Results}

Table 1 shows anthropometrics, socio-demographic and lifestyle characteristics of the participants at baseline and at follow-up. During this period, the decrease in the absolute values of DBP was similar in boys and girls (on average $3.9 \mathrm{mmHg}$ ). Boys at baseline and at follow-up had a significantly higher SBP than girls ( $\mathrm{p}_{\text {between subjects }} \mathrm{p} \leq 0.001$ ).

Table 2 shows the associations of SBP and DBP levels at follow-up with intakes of fruit and/or vegetables per day at baseline. In girls, an increase in $100 \mathrm{~g}$ of fruit per day was significantly associated with a $0.5 \mathrm{mmHg}$ decrease in DBP late in adolescence, after adjustment for confounders (Table 2).

\section{Discussion}

In this study, we analysed the relevance of fruit intake on later BP in apparently healthy adolescents. In girls, consumption of fruit was significantly associated with a 
Table 1 Participants' characteristics.

\begin{tabular}{|c|c|c|c|c|c|c|}
\hline & \multicolumn{2}{|l|}{ All $\mathrm{N}=606$} & \multicolumn{2}{|l|}{ Boys $\mathrm{N}=314$} & \multicolumn{2}{|l|}{ Girls N $=292$} \\
\hline & Baseline & Follow-up & Baseline & Follow-up & Baseline & Follow-up \\
\hline Age (years) & $14.4(1.8)$ & $16.4(1.8)$ & $14.6(1.8)$ & $16.6(1.8)$ & $14.2(1.7)^{\mathrm{c}}$ & $16.2(1.7)^{\mathrm{d}}$ \\
\hline Diastolic BP (mmHg) & $64.1(8.1)$ & $60.2(8.2)^{a}$ & $63.9(8.3)$ & $60.6(8.3)$ & $64.2(7.8)$ & $59.7(8.0)$ \\
\hline Systolic BP (mmHg) & $120.0(13.6)$ & $116.8(11.9)^{\mathrm{a}}$ & $122.0(14.5)$ & $120.3(12.1)^{\mathrm{b}}$ & $117.8(12.1)^{\mathrm{c}}$ & $113.0(10.4)^{\mathrm{b}, \mathrm{d}}$ \\
\hline \multicolumn{7}{|l|}{$\begin{array}{l}\text { Anthropometric } \\
\text { variables }\end{array}$} \\
\hline Height (m) & $1.6(0.1)$ & $1.7(0.1)^{a}$ & $1.6(0.1)$ & $1.7(0.1)^{b}$ & $1.6(0.1)^{\mathrm{c}}$ & $1.6(0.1)^{\mathrm{b}, \mathrm{d}}$ \\
\hline Weight (kg) & $55.1(12.8)$ & $61.3(12.2)^{a}$ & $57.5(14.2)$ & $65.0(12.8)^{\mathrm{b}}$ & $52.6(10.5)^{\mathrm{c}}$ & $57.4(10.0)^{\mathrm{b}, \mathrm{d}}$ \\
\hline BMI $\left(\mathrm{kg} / \mathrm{m}^{2}\right)$ & $21.2(3.6)$ & $22.1(3.5)^{\mathrm{a}}$ & $21.2(3.6)$ & $22.0(3.5)$ & $21.2(3.7)$ & $22.2(3.6)$ \\
\hline Waist circumference & $72.9(9.8)$ & $75.8(9.5)^{\mathrm{a}}$ & $74.1(9.9)$ & $77.2(9.4)$ & $71.6(9.5)^{c}$ & $74.3(9.3)^{d}$ \\
\hline Socioeconomic status & $6.5(1.6)$ & - & $6.3(1.7)$ & - & $6.6(1.5)$ & - \\
\hline Fruit (g/day) & $\begin{array}{l}223.2 \\
(132.3 ; 380.1)\end{array}$ & $\begin{array}{l}202.3 \\
(115.6 ; 353.6)^{a}\end{array}$ & $\begin{array}{l}210.4 \\
(125.5 ; 376.2)\end{array}$ & $\begin{array}{l}191.4 \\
(111.5 ; 345.2)\end{array}$ & $\begin{array}{l}246.9 \\
(140.9 ; 386.8)\end{array}$ & $\begin{array}{l}212.1 \\
(122.1 ; 357.4)\end{array}$ \\
\hline Vegetables (g/day) & $\begin{array}{l}273.7 \\
(121.6 ; 473.4)\end{array}$ & $\begin{array}{l}263.5 \\
(140.4 ; 419.4)^{a}\end{array}$ & $\begin{array}{l}245.5 \\
(107.8 ; 458.3)\end{array}$ & $\begin{array}{l}236.8 \\
(124.7 ; 378.8)\end{array}$ & $\begin{array}{l}292.0 \\
(131.4 ; 497.5)\end{array}$ & $\begin{array}{l}297.4 \\
(151.6 ; 471.8)^{\mathrm{c}}\end{array}$ \\
\hline $\begin{array}{l}\text { Fruit and } \\
\text { vegetables (g/day) }\end{array}$ & $\begin{array}{l}375.8 \\
(224.3 ; 605.7)\end{array}$ & $\begin{array}{l}489.8 \\
(313.9 ; 753.4)^{\mathrm{a}}\end{array}$ & $\begin{array}{l}369.5 \\
(225.4 ; 590.2)\end{array}$ & $\begin{array}{l}463.6 \\
(305.1 ; 631.6)\end{array}$ & $\begin{array}{l}383.7 \\
(223.1 ; 629.3)\end{array}$ & $\begin{array}{l}532.3 \\
(328.1 ; 827.6)^{\mathrm{c}}\end{array}$ \\
\hline $\begin{array}{l}\text { Cardiorespiratory } \\
\text { fitness }-\mathrm{VO}_{2} \max \\
(\mathrm{mL} / \mathrm{kg} / \mathrm{min})\end{array}$ & $42.5(6.6)$ & $42.2(7.7)$ & $45.8(6.3)$ & $\begin{array}{l}46.5 \\
(7.0)^{\mathrm{b}}\end{array}$ & $39.0(4.8)^{\mathrm{c}}$ & $37.6(5.3)^{\mathrm{b}}$ \\
\hline
\end{tabular}

Results from ANOVA with repeated measures. All variables are expressed as mean (SD) except for fruit and vegetable consumption that are expressed as median (P25-P75).

a) Significant differences over time in total sample $(\mathrm{p}<0.05)$; b) significant differences over time between sexes $(\mathrm{p}<0.05)$; $\mathrm{c})$ significant differences at baseline between sex $(\mathrm{p}<0.05)$; $\mathrm{d})$ significant differences at follow-up between $\operatorname{sex}(\mathrm{p}<0.05)$.

decrease in DBP over a two-year follow-up, after adjustments for potential confounders. In practise, an increase in one portion of fruit, such as a medium apple per day $(\sim 160 \mathrm{~g})$ was associated with a $0.8 \mathrm{mmHg}$ decrease in DBP in girls. These results are of clinical significance since the elevated DBP appears to be a more consistent and independent prognostic indicator of adult cardiovascular risk [26]. This is particularly important because small reductions in BP may have important public health effects [27].

Our results agree with those reported in previous studies on children and adolescents, where there was an inverse association between fruit and vegetable consumption and BP [7-10]. In pre-pubertal children an increase in $100 \mathrm{~g}$ of fruit and vegetable intake was associated with a reduction of $0.4 \mathrm{mmHg}$ SBP and DBP [9]. Furthermore, another study reported that an increase in $100 \mathrm{~g}$ of fruit per day was related to a reduction of $0.9 \mathrm{mmHg}$ in SBP in adult women [10], whereas Mellendick et al. [8] found an inverse association between fruit intake and DBP. It seems that fruit consumption may benefit BP because of its antioxidant level and lowering oxidative stress effect, along with high contents of potassium, magnesium and fibre [6]. Apart from this, the exact mechanisms by which the compounds of fruit and vegetables influence BP are not fully understood, though it has been suggested that they may be a mirror of a healthier pattern [7]. Indeed, some healthy dietary patterns such as the DASH (Dietary Approaches to Stop Hypertension) diet are characterized by a high consumption of whole grain, fruit and vegetables, low-fat dairy products, lean meat, poultry and fish, and nuts and legumes; and previous clinical trials emphasizing this diet have reported an inverse association between this diet and DBP in children 5 to 8 years-old [28].

Our study suggests sex differences in the association between fruit and vegetable consumption and BP. The

Table 2 Results of GLM for the association between baseline fruit and vegetable intake and blood pressure at follow-up.

\begin{tabular}{|c|c|c|c|c|c|c|c|c|}
\hline & Girls & DBP & Boys & $\mathrm{p}$ & Girls & SBP & Boys & $\mathrm{p}$ \\
\hline & $\mathrm{B}(95 \% \mathrm{CI})$ & $\mathrm{p}$ & $\mathrm{B}(95 \% \mathrm{CI})$ & & $\mathrm{B}(95 \% \mathrm{CI})$ & $\mathrm{p}$ & $\mathrm{B}(95 \% \mathrm{CI})$ & \\
\hline Whole fruit (g/d) & $\begin{array}{l}-0.005 \\
(-0.01 ;-0.0002)\end{array}$ & 0.038 & $\begin{array}{l}-0.0003 \\
(-0.004 ; 0.003)\end{array}$ & 0.866 & $\begin{array}{l}-0.004 \\
(-0.01 ; 0.002)\end{array}$ & 0.170 & $\begin{array}{l}0.0004 \\
(-0.005 ; 0.006)\end{array}$ & 0.888 \\
\hline Vegetables (g/d) & $\begin{array}{l}-0.0004 \\
(-0.004 ; 0.004)\end{array}$ & 0.861 & $\begin{array}{l}0.001 \\
(-0.002 ; 0.005)\end{array}$ & 0.462 & $\begin{array}{l}0.002 \\
(-0.003 ; 0.007)\end{array}$ & 0.389 & $\begin{array}{l}-0.0004 \\
(-0.005 ; 0.004)\end{array}$ & 0.884 \\
\hline $\begin{array}{l}\text { Fruit and } \\
\text { vegetables }(\mathrm{g} / \mathrm{d})\end{array}$ & $\begin{array}{l}-0.003 \\
(-0.002 ; 0.002)\end{array}$ & 0.484 & $\begin{array}{l}0.001 \\
(-0.002 ; 0.004)\end{array}$ & 0.490 & $\begin{array}{l}-0.001 \\
(-0.005 ; 0.004)\end{array}$ & 0.802 & $\begin{array}{l}-0.0003 \\
(-0.004 ; 0.004)\end{array}$ & 0.987 \\
\hline
\end{tabular}

Adjusted for age, height SDS, waist circumference SDS, socioeconomic status, pubertal status, cardiorespiratory fitness, misreporting, total energy intake, potassium, sodium and baseline measure of the variable of interest.

g/d- means gram/day. B- unstandardized Beta. 
differences are in accordance with previous studies where a pattern similar to DASH diet was associated to a decrease in DBP in girls [12]. To explain the difference found in our study, we analysed the possibility that boys and girls reported differently the consumption of fruit and vegetable, although their intake was not significantly different. It is possible that there are relevant changes in hormonal status during puberty. Indeed, puberty onset at younger ages seems to be associated with increased BP in boys and girls $[3,4]$. A previous longitudinal study found that a decrease in BP was associated to higher intakes of fruit and vegetable intake only in pre-pubertal stages [9]. Therefore, we accounted for pubertal stage as a confounder in all the analysis performed.

In our study, no independent beneficial association of vegetable consumption was found, contrary to previous studies $[8,9,13,29]$, but similarly to what others have reported [12]. The absence of an association of vegetable consumption on BP in this study may be associated not only to the types of vegetables consumed, but also to its cooking processes. Indeed, processing vegetables may change their nutritional content and chemical composition and the type of vegetables consumed may differently influence BP [29]. In addition, we included vegetable soup in the total vegetable intake, and although vegetable soup is a significant contributor of the daily intake of vegetables among Portuguese adolescents, it is also known that vegetable soup contributes up to $7 \%$ of total sodium intake [30]. Nevertheless, we repeated the analysis excluding vegetable soup, and the results remained non-significant [unstandardized beta: $-0.001 \mathrm{mmHg}$ (95\%CI: -0.004 ; $0.003), \mathrm{p}=0.728$ for DBP and unstandardized beta: $0.002 \mathrm{mmHg}(95 \% \mathrm{CI}:-0.002 ; 0.007), \mathrm{p}=0.318$ for SBP] (data not shown), suggesting that in our data, the inclusion of vegetable soup was not a significant contributor to an increase in BP.

This study has several strengths that should be highlighted. First, the longitudinal design of our study allowed to explore the associations between fruit and vegetable intake and BP over time. Second, the adjustment for major potential confounders including anthropometry, cardiorespiratory fitness, socioeconomic status, pubertal stage, energy intake and dietary intake, misreporting, which can account for part of the determinants of BP. To the best of our knowledge, this is the first study that accounted for all of these variables, including a valid and accurate cardiorespiratory fitness field test [22], which offers evidence about the independent impact of fruit and vegetable intake on BP. Third, the non-inclusion of fruit juice in the whole fruit intake is an additional strength, since recent studies found positive associations between habitual fruit juice consumption and BP [16].

The present study has also limitations. The dietary intake data, using a self-reported semi-quantitative questionnaire cannot control for reporting bias, and adolescents had to be highly motivated to recall food consumption [15]. Nevertheless, adolescents had oral instructions about FFQ from the data collectors, which may have improved quality of the information gathered. In addition, we adjusted the analysis for misreporting, preventing at least in part, reporting bias. In our study, vegetable intake included vegetable soup, is likely to reflect an overestimation of vegetable consumption, due to the significant water content of vegetable soup. Nonetheless, even when performing analysis excluding vegetable soup from the total vegetable intake, the associations with total vegetable intake and BP remained non-significant. Another limitation is related to the measurement of BP. It is known that BP changes during the day, and that an isolated measurement may not represent a person's usual BP. Moreover we did collect biomarkers to validate dietary intake.

Our study supports the concept that fruit consumption may influence BP, independently of several confounders. Monitoring health and environmental conditions, as well as lifestyle, early in adolescence may have a positive impact in BP in later adolescence. Although no significant results were found for vegetable intake; vegetable consumption should continue to be encouraged among adolescents as its benefits go beyond BP.

\section{Conflict of interest}

The authors declare they have no competing interests to declare.

\section{Acknowledgements}

This study was supported by the Research Centre on Physical Activity Health and Leisure (CIAFEL) of the Faculty of Sport, University of Porto and by FCT grant BD88984/ 2012 (J. Oliveira-Santos); The Research Centre on Physical Activity Health and Leisure (CIAFEL) is supported by UID/ DTP/00617/2013 (FCT); the author C. Agostinis-Sobrinho was given Doctoral scholarship from the Brazilian government by CAPES (Coordination of Improvement of Higher Education Personnel) (Proc: 9588-13-2).

The authors gratefully acknowledged the participation of all adolescents and their parents, teachers and schools of the LabMed Study. They also acknowledge the cooperation of volunteer's subjects and the Research Centre in Physical Activity, Health and Leisure (University of Porto) for the sponsoring the LabMed Study.

\section{Appendix A. Supplementary data}

Supplementary data related to this article can be found at https://doi.org/10.1016/j.numecd.2018.05.014.

\section{References}

[1] Rosner B, Cook NR, Daniels S, Falkner B. Childhood blood pressure trends and risk factors for high blood pressure: the NHANES experience 1988-2008. Hypertension 2013;62:247-54.

[2] Sun SS, Grave GD, Siervogel RM, Pickoff AA, Arslanian SS, Daniels SR. Systolic blood pressure in childhood predicts hypertension and metabolic syndrome later in life. Pediatrics 2007;119: 237-46. 
[3] Bubach S, Loret De Mola C, Hardy R, Dreyfus J, Santos AC. Horta BL: early menarche and blood pressure in adulthood: systematic review and meta-analysis. J Public Health (Oxf) 2017:1-9.

[4] Kwok M, Leung G, Schooling C. Pubertal testis volume, age at pubertal onset, and adolescent blood pressure: Evidence from Hong Kong's "Children of 1997" birth cohort. Am J Hum Biol 2017;29.

[5] Labbrozzi D, Robazza C, Bertollo M, Bucci I, Bortoli L. Pubertal development, physical self-perception, and motivation toward physical activity in girls. J Adolesc 2013;36:759-65.

[6] Cohen J, Lehnerd M, Houser R, Rimm E. Dietary Approaches to Stop hypertension diet, weight status, and blood pressure among children and adolescents: national health and nutrition examination surveys 2003-2012. J Acad Nutr Diet 2017;117:1437-44. e1432.

[7] Moore LL, Singer MR, Bradlee ML, Djousse L, Proctor MH, Cupples LA, et al. Intake of fruits, vegetables, and dairy products in early childhood and subsequent blood pressure change. Epidemiology 2005;16:4-11.

[8] Mellendick K, Shanahan L, Wideman L, Calkins S, Keane S, Lovelady C. Diets rich in fruits and vegetables are associated with lower cardiovascular disease risk in adolescents. Nutrients 2018; 10 .

[9] Shi L, Krupp D, Remer T. Salt, fruit and vegetable consumption and blood pressure development: a longitudinal investigation in healthy children. Br J Nutr 2014;111:662-71.

[10] Krupp D, Shi L, Egert S, Wudy S, Remer T. Prospective relevance of fruit and vegetable consumption and salt intake during adolescence or blood pressure in young adulthood. Eur J Nutr 2015;54 1269-79.

[11] Kwan MW, Wong MC, Wang HH, Liu KQ Lee CL, Yan BP, et al. Compliance with the dietary Approaches to Stop hypertension (DASH) diet: a systematic review. PLoS One 2013;8:e78412.

[12] Moore LL, Bradlee ML, Singer MR, Qureshi MM, Buendia JR, Daniels SR. Dietary Approaches to Stop Hypertension (DASH) eating pattern and risk of elevated blood pressure in adolescent girls. Br J Nutr 2012;108:1678-85.

[13] Jaaskelainen P, Magnussen CG, Pahkala K, Mikkila V, Kahonen M, Sabin MA, et al. Childhood nutrition in predicting metabolic syndrome in adults: the cardiovascular risk in Young Finns Study. Diabetes Care 2012;35:1937-43.

[14] Agostinis-Sobrinho C, Santos R, Moreira C, Abreu S, Lopes L, Oliveira-Santos J, et al. Association between serum adiponectin levels and muscular fitness in Portuguese adolescents: LabMed Physical Activity Study. Nutr Metabol Cardiovasc Dis 2016;26:517-24.

[15] Willett W. Food frequency methods. In: Willett WUSA, editor. Nutritional epidemiology. 3rd ed. Oxford University Press; 2013. p. 70-96.
[16] Pase MP, Grima N, Cockerell R, Pipingas A. Habitual intake of fruit juice predicts central blood pressure. Appetite 2015;84:68-72.

[17] Lohmann T, Roche A, Martorell R. Anthropometric standardization reference manual. Champaign, Ill: Human Kinetics Books; 1988.

[18] Williams JS, Brown SM, Conlin PR. Blood-pressure measurement. N Engl J Med 2009;360:e6.

[19] McCrindle BW. Assessment and management of hypertension in children and adolescents. Nat Rev Cardiol 2010;7:155-63.

[20] Currie C, Molcho M, Boyce W, Holstein B, Torsheim T, Richter M. Researching health inequalities in adolescents: the development of the Health Behaviour in School-Aged Children (HBSC) family affluence scale. Soc Sci Med 2008;66:1429-36.

[21] Tanner JM, Whitehouse RH. Clinical longitudinal standards for height, weight, height velocity, weight velocity, and stages of puberty. Arch Dis Child 1976;51:170-9.

[22] Leger LA, Mercier D, Gadoury C, Lambert J. The multistage 20 metre shuttle run test for aerobic fitness. J Sports Sci 1988;6:93-101.

[23] Ward DS, Evenson KR, Vaughn A, Rodgers AB, Troiano RP. Accelerometer use in physical activity: best practices and research recommendations. Med Sci Sports Exerc 2005;37:S582-8.

[24] Trost SG, Pate RR, Sallis JF, Freedson PS, Taylor WC, Dowda M, et al. Age and gender differences in objectively measured physical activity in youth. Med Sci Sports Exerc 2002;34:350-5.

[25] Black AE. Critical evaluation of energy intake using the Goldberg cut-off for energy intake:basal metabolic rate. A practical guide to its calculation, use and limitations. Int J Obes Relat Metab Disord 2000;24:1119-30.

[26] Sundstrom J, Neovius M, Tynelius P, Rasmussen F. Association of blood pressure in late adolescence with subsequent mortality: cohort study of Swedish male conscripts. Bmj 2011;342:d643.

[27] Cook NR, Cohen J, Hebert PR, Taylor JO, Hennekens CH. Implications of small reductions in diastolic blood pressure for primary prevention. Arch Intern Med 1995;155:701-9.

[28] Novotny R, Nigg C, Li F, Wilkens L. Pacific kids DASH for health (PacDASH) randomized, controlled trial with DASH eating plan plus physical activity improves fruit and vegetable intake and diastolic blood pressure in children. Child Obes 2015;11:177-86.

[29] Chan Q, Stamler J, Brown IJ, Daviglus ML, Van Horn L, Dyer AR, et al. Relation of raw and cooked vegetable consumption to blood pressure: the INTERMAP Study. J Hum Hypertens 2014;28:353-9.

[30] Lopes C, Torres D, Oliveira A, Severo S, Alarcão V, Guiomar S, et al. Inquérito Alimentar Nacional e de Atividade Física IAN-AF 20152016 Relatório Parte II [National food survey and of Physical Activity IAN-AF 2015-2016 Report Part II]. Porto. University of Porto; 2017. 